\title{
RELATIONSHIP STRENGTH DAN HUBUNGANNYA DENGAN KEPUASAN PELANGGAN
}

\author{
Ahmad Faisal \\ Dosen Tetap Magister Manajemen Unsurya \\ ebankfaisal@gmail.com
}

\begin{abstract}
ABSTRAK
Penelitian ini dilatarbelakangi, mengingat bahwa dewasa ini semakin banyak perusahaan yang menjalankan perusahaannya dengan mengalihkan strategi mereka ke pemasaran dengan menjalin hubungan dan kerjasama yang kuat antara perusahaan dengan pelanggan yang popular dengan sebutan relationship strength, dengan tujuan untuk memperlancar pemasaran barang dan jasa dan untuk meningkatkan keuntungan perusahaan. Kemudian untuk mengkaji berbagai variasi dalam relationship strength dan dampaknya dengan kepuasan pelanggan pada maskapai penerbangan (airline), dapat difokuskan pada tiga variasi atau dimensi yang membentuk relationship strength yaitu: trust, commitment, dan relationalism.

Ada tiga hipotesis yang diajukan dalam penelitian ini yaitu: (Ha1) : Terdapat dampak kepercayaan dengan kepuasan pelanggan). (Ha2) : Terdapat dampak komitmen dengan kepuasan pelanggan (Ha3) : Terdapat dampak relationalism dengan kepuasan pelanggan

Dari hasil penelitian ini terbukti bahwa ketiga hipotesis yang diajukan semuanya terbukti gagal ditolak. Dari hasil pengujian Hipotesis Pertama (Ha1) dapat dibuktikan bahwa terdapat dampak yang positif antara kepercayaan dengan kepuasan pelanggan. Hasil uji Hipotesis Kedua (Ha2) juga terbukti bahwa terdapat dampak yang positif antara komitmen dengan kepuasan pelanggan. Hipotesis Ketiga (Ha3) juga terbukti bahwa terdapat dampak yang positif antara relationalism dengan kepuasan pelanggan. Dampak antara berbagai variasi atau dimensi-dimensi yang membentuk relationship strength dengan kepuasan pelanggan secara keseluruhan sangat kuat. Juga terdapat pengaruh Relationship Strength terhadap kepuasan pelanggan. Dari ketiga dimensi relationship strength diatas, maka yang paling tinggi pengaruhnya terhadap kepuasan pelanggan adalah kepercayaan

Implikasi manajerial dari hasil penelitian ini agar pihak maskapai penerbangan harus betuk betul menjaga dan meningkatkan kepercayaan pelanggan dan komitmen dan relationalism agar jalinan hubungan semakin kuat baik antara pelanggan dengan maskapai penerbangan. Juga, agar dipertimbangkan pemberian kompensasi yang cukup dan seimbang dengan tugas-tugas karyawan yang langsung berhubungan dengan pelanggan mereka karena tugas-tugas mereka cukup berat dan terkait dengan kepuasan pelanggan.
\end{abstract}

Kata kunci : relationship strength, kepercayaan, komitmen dan relationalism

\section{PENDAHULUAN}

Dewasa ini semakin banyak perusahaan yang menjalankan perusahaannya dengan mengalihkan strategi mereka dari pemasaran transaksi (transaction marketing) ke pemasaran dengan menjalin hubungan dan kerjasama yang kuat antara perusahaan dengan pelanggan yang populer dengan sebutan relationship strength, dengan tujuan untuk memperlancar pemasaran barang dan jasa dan untuk meningkatkan keuntungan perusahaan.

Jalinan hubungan yang kuat (relationship strength) antara perusahaan dengan pelanggan tampaknya menjadi kunci dalam memenangkan dan mempertahankan kelangsungan perusahaan karena dilain pihak sekarang ini pelanggan sudah mempunyai banyak pilihan (choice) 
baik produk maupun perusahaan dan pelanggan sekarang ini menghadapi suatu rangkaian luas pilihan merek, harga, dan pemasok. Pelanggan tentu akan memilih tawaran pemasaran yang memberikan kepada mereka nilai tertinggi.

Kekuatan hubungan (relationship strength) antara perusahaan dengan pelanggan mengacu pada ikatan hubungan yang kuat dan mencerminkan kemampuan mereka untuk mempertahankan dirinya baik dari tantangan eksternal maupun internal terhadap hubungan tersebut. Outcome dari sebuah relationship yang berhasil dapat diekspresikan dalam hal kerjasama dan adaptability, kualitas dari performance, satisfaction (kepuasan) dan durability (lamanya) hubungan tersebut. Kunci keberhasilannya terletak pada kombinasi dari trust, komitmen dan orientasi hubungan antar perusahaan dengan pelanggan (relasionalism) (Hausman, 2001 : 601-605).

bisnis dicirikan oleh jenis relasinya (relational nature), termasuk saling percaya (mutual trust), orientasi jangka panjang, dan tujuan bersama dari hubungan, seperti saling ketergantungan yang tinggi (high interdependency), dan menyoroti kebutuhan atas perilaku-perilaku relasional, khususnya saling timbal-balik kerjasama, dan menepati janji.

Banyak ahli saat ini yang turut mengajukan pertimbangan agar perusahaan dalam memperlancar proses pemasarannya dapat menerapkan ikatan hubungan yang kuat (relationship strength), apapun jenis industrinya, terutama di dalam pasar-pasar konsumen (consumer markets). Berdasarkan hasil studi empiris banyak ahli berpendapat bahwa sejumlah konstruk yang tampaknya memiliki kemampuan untuk menciptakan sejumlah jenis dari ikatan hubungan yang kuat (relationship strength) yang dikonseptualkan terutama adalah : kepercayaan (trust), komitmen (commitment) dan norma-norma relasional (relasionalism) (Hausman, 2001 : 601-605).

Pendekatan yang lebih baik untuk mempertahankan pelanggan adalah dengan memberikan kepuasan pelanggan yang tinggi, sehingga pelanggan akan lebih sulit bagi saingannya untuk menerobos halangan dengan menawarkan harga lebih murah atau rangsangan lain. Kunci mempertahankan pelanggan adalah dengan memberikan kepuasan yang tinggi kepada pelanggan (Kotler, 2000 : 49).

Perusahaan masa kini lebih memperhatikan tingkat kehilangan pelanggan dan mengambil langkah untuk mengurangi kehilangan pelanggannya antara lain dengan menerapkan relationship strength dalam proses pemasaran produknya. Dengan demikian, kepercayaan (trust), komitmen (commitment) dan relationalism dapat dikombinasikan untuk menghasilkan outcome yang diinginkan, seperti menghasilkan kepuasan pelanggan. 
Dari uraian tersebut di atas, maka rumusan masalah penelitian dapat dibuat sebagai berikut :

1. Apakah terdapat hubungan kepercayaan (trust) terhadap kepuasan pelanggan (customers' satisfaction)?

2. Apakah terdapat hubungan komitment (commitment) terhadap kepuasan pelanggan (customers' satisfaction) ?

3. Apakah terdapat hubungan relationalism terhadap kepuasan pelanggan (customers' satisfaction)?

1. Kekuatan Hubungan (Relationship Strength) Dalam Hubungan Bisnis

Konsep dari kekuatan hubungan (relationship strength) belum pernah disampaikan sebelumnya, namun pemahaman bahwa ada beberapa relationship yang lebih kuat dari pada yang lainnya telah melandasi banyak dari studistudi tentang business relationship atau hubungan bisnis. Hal ini dapat dilihat dari pernyataan Hausman (2001 : 603) bahwa : "The concept of relationship strength has never been articulated before, but the notion that some relationships are stronger than others underlies many of studies of business relationships"

Menurut Hausman (2001 : 603), definisi dari kekuatan hubungan (relationship strength) adalah : "Relationship strength, as conceptually definded, refers to the teis between relational partners and reflects their ability to weather both internal and external challenges to relationship". Jadi, kekuatan hubungan (relationship strength) secara konseptual dapat didefinisikan, mengacu pada ikatan hubungan antara relasi dan mencerminkan kemampuan mereka untuk mempertahankan dirinya baik dari tantangan eksternal maupun internal terhadap hubungan tersebut.

Dalam pemasaran dan bisnis juga dikenal relationship yang populer disebut relationship marketing. Relationship dalam pemasaran dapat dilakukan dengan jalan menjalin hubungan baik dan kerjasama perusahaan dengan pelanggan yang ditujukan untuk memperlancar pemasaran produk/jasa dan menciptakan kekuatan hubungan (relationship strength) serta meningkatkan keuntungan (profitabilitas).

2. Hasil Studi Empiris Tentang Kekuatan Pengaruh (Relationship Strength)

Relationship strength (kekuatan hubungan) menawarkan janji teoritis untuk membantu dalam mengkategorikan berbagai relationship dan membantu dalam menjelaskan mengapa ada beberapa relationship lebih efektif dalam mencapai hasil gabungan (joint outcomes) dibanding sejumlah relationship lainnya. Hal ini dapat dilihat dari pernyataan Hausman (2001 : 603) bahwa : "Relationship strength offers theoritical promise for helping categorize relationships and helps explain why some relationships are more effcective at achieving joint outcomes than others".

Dari hasil studi empiris banyak ahli berpendapat bahwa sejumlah konstruk yang 
tampaknya memiliki kemampuan untuk menciptakan sejumlah jenis dari ikatan hubungan yang dikonseptualkan terutama adalah : kepercayaan (trust), komitmen (commitment) dan norma-norma relasional (hubungan).

Hausman (2001 : 603) menyatakan bahwa : "From an empirical standpoint, we have reviewed extant literature, puling constructs that appeared to have the ability to create the types of ties conceptualizedspecifically trust, commitment, and relational norms. Prior studies empirical evidence that some relationships are characterized as more trusting, more relationally oriented than others (Ganesan, 1994; Hamilton and Singh, 1991; Moorman etal., 1992; Morgan and Hunt, 1994)".

Dari pendapat di atas dapat dilihat bahwa, sejumlah studi sebelumnya menghasilkan bukti empirik dimana beberapa relationship dicirikan oleh adanya keadaan yang lebih dapat dipercaya (trusting), lebih berkomitmen (commitment), atau lebih berorientasi pada hubungan (relationship oriented) ketimbang sejumlah relationship lain (Ganesan, 1994; Hamilton dan Singh ,1991; Moorman dkk,1992; Morgan dan Hunt, 1994).

yang mendukung kerjasama dan pengambilan keputusan bersama yang dapat membantu kelanggengan relationship. Oleh karenanya, maka hubungan yang kurang dapat dipercayai dapat mempertahankan
Menurut Hausman (2001: 603) bahwa

"While the manajerial importance of these constructs has been tested independently, it is conceptually appealing to combine the constructs into a summary construct reflecting the strength of the relationship. Using a summary construct rather than each construct independently, implies that the factors work in concert to create an atmosphere supportive of cooperation and mutal decision- making that help ensure relationship survival. Therefore, less trusting relationships maintain functionality when they contain higher degrees of commitment and/or relationism".

Dari pendapat di atas, dapat dinyatakan karena arti penting manajerial dari konstruk- konstruk yang telah diujikan secara independent, maka hal ini secara konseptual menarik untuk mengkombinasikan konstruk ke dalam sebuah konstruk ikhtisar (summary construct) yang mencerminkan kekuatan dari relationship. Dengan menggunakan sebuah summary construct,_ketimbang masing-masing konstruk secara independen, menyiratkan bahwa sejumlah faktor saling bekerja untuk menciptakan sebuah atmosfir fungsionalitas bilamana hubungan tersebut memiliki komitmen dan/atau relationalism.

\section{Dimensi-dimensi Dari Kekuatan Hubungan (Relationship Strength)}


Pada uraian di atas telah disebutkan ada tiga dimensi yang membentuk kekuatan hubungan (relationship strength) dalam bisnis yaitu: kepercayaan (trust), komitmen (commitment) dan norma-norma relasional (hubungan). Antesedents dan consequences dari ketiga tiga dimensi yang membentuk kekuatan hubungan (relationship strength) dapat dilihat dalam Gambar di bawah ini.

Antesedents Relationship Strength Consequences

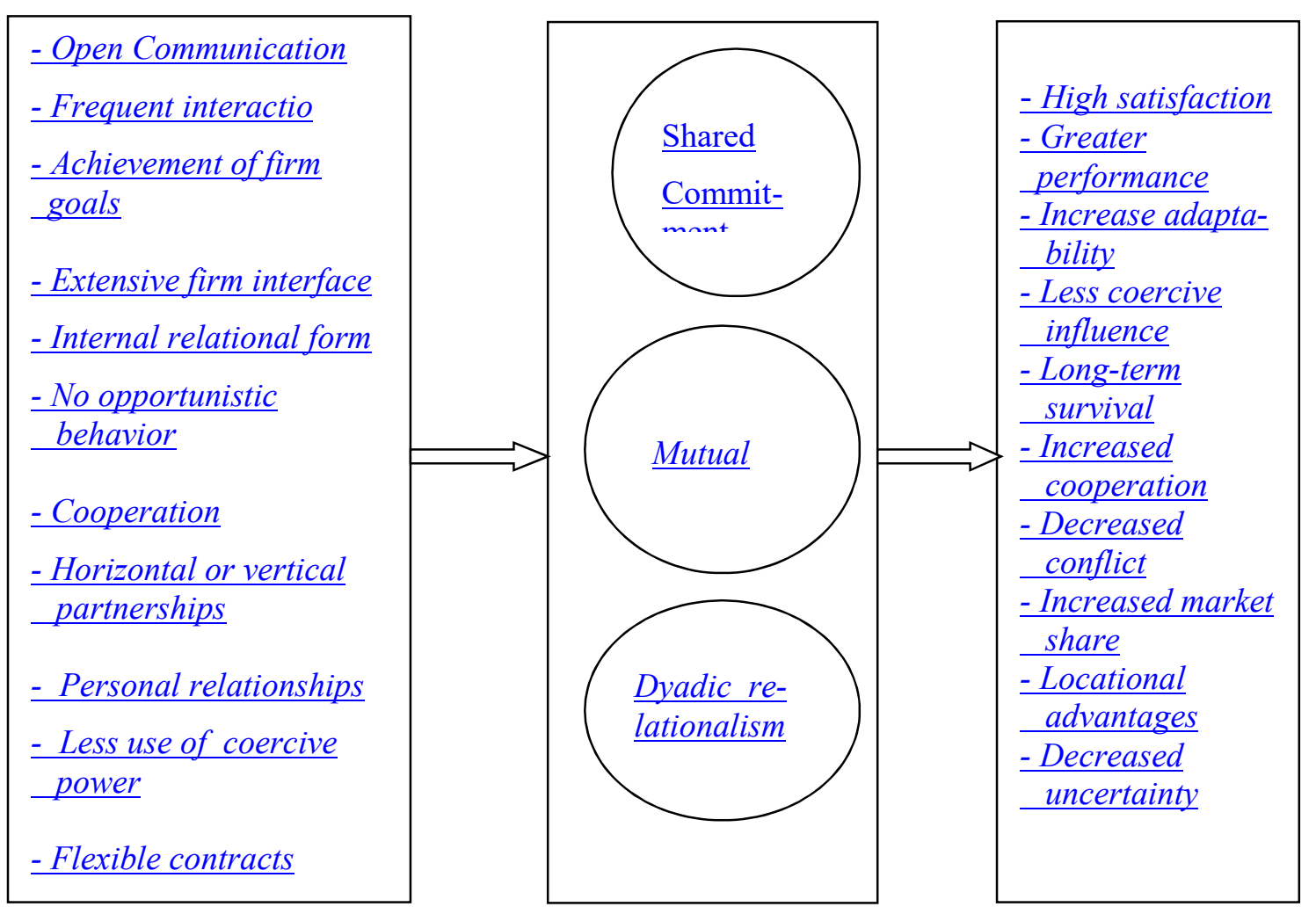

Gambar . Antesedents and Consequences of Relationship Strength (Hausman, 2000:603) 
Pada Gambar di atas, menunjukkan gambar yang berisikan banyak lingkage (keterkaitan hubungan) antara masingmasing konstruk yang terdiri atas relationship strength dan beragam hasil hubungan (relational outcomes) yang positif. Berikut ini dijelaskan satu per satu dari tiga dimensi yang membentuk kekuatan hubungan (relationship strength) dalam bisnis yaitu : kepercayaan (trust), komitmen (commitment) dan norma-norma relasional (hubungan).

\section{a. Trust}

Menurut Hausman (2001 : 603) bahwa :

"Trust is defined as "a firm belief that another company will performa actions that will result in positive outcomes for the firm and not engage in unexpected behaviors with negative outcomes" (Anderson and Narus, 1990). Morgan and Hunt (1994) specify more exactly what trust means in interorganizational relationships with their definition of trust as "when one party has confidence in an exchange partners's reliability and integrity". From these definition, come propositions that trust acts to promote relationship success through reduced uncertainty and likelihood of opportunistic behavior (Das and Teng, 1998)”.
Dari pendapat di atas, dapat dilihat bahwa kepercayaan (trust) didefinisikan sebagai "keyakinan dari sebuah perusahaan bahwa perusahaan yang lain akan melaksanakan sejumlah tindakan yang akan menghasilkan outcome yang positif bagi perusahaan tersebut dan tak terlibat dalam sejumlah perilaku yang tak diharapkan dengan outcome yang negatif". (Anderson dan Narus ,1990). Morgan dan Hunt (1994) menspesifikasikan lebih jelas tentang apa arti trust dalam inter-organizational relationship atau hubungan antar organisasi dengan definisi trust yaitu "ketika salah satu pihak menaruh keyakinan pada reliabilitas dan integritas dari seorang exchange partner (partner pertukaran)". Dari definisi-definisi ini, muncullah sejumlah proposisi yang menyebutkan bahwa trust dapat meningkatkan keberhasilan hubungan melalui berkurangnya ketidakpastian dan kemungkinan adanya perilaku oportunistik (Das dan Teng, 1998).

Menurut Hausman (2001 : 604) bahwa : "Prior research has postulated trust as both an antecedent to successful long-term relationships (cf. Morgan and Hunt, 1994) and outcome of these relationships (Jones and George, 1998; Simpson and Mayo, 1997)". Artinya, dari hasil riset sebelumnya telah mendalilkan bahwa trust adalah anteseden (pendahulu) atas keberhasilan long-term relationship (hubungan jangka panjang) (lihat Morgan 
dan Hunt, 1994) maupun outcome dan sejumlah relationship tersebut (Jones dan George, 1998; Simpson dan Mayo, 1997).

$$
\text { Begitu pula halnya, trust }
$$
merupakan proses yang iteratif atau berulang, dimana para partner saling mempercayai untuk melaksanakan sejumlah tugas tertentu dan bertindak demi kepentingan yang paling utama dari relationship tersebut (Hausman, 2001 : 604). Dari waktu ke waktu, pada saat partner relasi mampu melaksankan tugastugas tersebut dengan cara-cara yang dapat diterima, maka rasa trust pada partner akan meningkat. Ini menunjukkan bahwa level of trust di antara anggota saluran (channel member) akan lebih rendah pada sejumlah interaksi ketimbang pada interaksi-interaksi relasional (Dwyer dkk, 1987; Mohr dan Nevin, 1990).

Menurut Hausman (2001 : 604) :

"In terms of measures of joint outcomes proposed here; trust has been empirically linked with : cooperation and adaptation (Morgan and Hnt, 1994); greater performance (Boyle et al., 1992; Simpson and Mayo, 1997); and plans to continue the relationship (Morgan and Hunt, 1994)".

Dari pendapat di atas, dapat dilihat bahwa dalam hal ukuran-ukuran dari joint outcomes yang diajukan di sini, trust telah secara empiris dikaitkan dengan :

kerjasama dan adaptasi (Morgan dan Hunt, 1994); performance yang lebih baik (Boyke dkk, 1992; Simpson dan Mayo, 1997); dan berbagai rencana untuk melanjutkan relationship tersebut (Morgan dan Hunt, 1994).

\section{b. Commitment}

Menurut Hausman (2001 : 603) bahwa :

"Commitment is defined as "an exchange partner's belief that an ongoing relationship with another is so important as to warrant maximum efforts at maintaining it; that is the committed party believes the relationship is worth working on to ensure that it endures indefinitely" (Morgan and Hunt, 1994,p.22)".

Dari pendapat di atas, commitment (komitmen) didefinisikan sebagai "keyakinan dari seorang exchange partner bahwa relationship yang terjalin selama ini dengan pihak lain adalah sangat penting untuk menjamin berbagai upaya maksimal yang dikerahkan untuk memeliharanya; dimana pihak yang berkomitmen meyakini bahwa relationship tersebut patut diteruskan untuk memastikan agar hubungan tersebut terjalin abadi" (Morgan dan Hunt, 1994, hal. 22).

Menurut Hausman (2001 : 603) bahwa : "More simply, commitment to relationship is defined as an "enduring desire to maintain a valued relationships..." Artinya, lebih sederhananya, komitmen terhadap relationship didefinisikan sebagai sebuah "keinginan yang berlangsung lama untuk memelihara sebuah relationship yang 
berharga" (Moorman dkk, 1992, hal. 318). Tanpa komitmen terhadap relationship perusahaan-perusahaan cenderung tidak akan melakukan investasi pada sejumlah investasi spesifik yang berkaitan dengan relationship atau mengkontribusikan sejumlah sumber daya lainnya untuk memastikan keberhasilan dari relationship tersebut (Williamson, 1996).

Seseorang akan berharap bahwa level of commitment akan lebih tinggi pada bentuk hubungan saluran (channel relationship) yang relational ketimbang transaksional karena transactional relationship biasanya menggunakan kontrak-kontrak jangka pendek, sementara itu bentuk-bentuk relational menggunakan kontrak-kontrak normatif untuk mengatur relationship tersebut (Gundlach dan Murphy, 1993; Ring dan Van de Ven, 1994).

Menurut Hausman (2001 : 604) : "Research links commitment to achievement of joint outcomes in the relationship, such as cooperation, adaptation, and continue (Anderson and Narus, 1990; Morgan and Hunt, 1994)..." Artinya, hasil riset juga menunjukkan ada kaitan komitmen dengan pencapaian atas joint income dalam relationship, seperti kerjasama, adaptasi, dan kesinambungan hubungan. Tampaknya ada juga sebuah interaksi antara komitmen dengan trust, dimana level of trust meningkat pada integritas dari seorang relational partner mampu meningkatkan komitmen perusahaan terhadap relationship tersebut (Morgan dan Hunt, 1994).

Pressey dan Mathews (2000:2)

juga mengatakan bahwa :

"Commitment and trust are the key drivers of co-operative relationships" (Hunt and Morgan, 1994). Kalafatis and Miller (1998), Beaton and Beaton (1995) and Russbult and Bunk (1993) also observed the importance of commitment, claiming that it is an indicator of stability and success within the relationship, and is ultimately essential for long-term relationships. Wilson (1995). Dwyer et. al., (1987) Scanzoni (1979) ans Ring and Van de Van (1992) further confirm that all relationships require trust to help them develop..."

Pressey dan Mathews dengan mengutip beberapa pendapat ahli, seperti di atas, tampak bahwa komitmen dan kepercayaan adalah pendorong utama dalam hubungan yang kooperatif. Komitmen adalah juga merupakan indikator stabilitas dalam relationship dan pada akhirnya sangat essential dalam hubungan jangka panjang. Wilson (1995), Dwyer et. al., (1987) Scanzoni (1979), Ring dan Van de Van (1992), juga menegaskan bahwa semua relationship membutuhkan trust (kepercayaan) agar dapat membantu pengembangan hubungan itu.

Carr (1992), Lamming (1992), dan Coviello dkk. (1998) juga mengamati 
bahwa apapun industrinya, adalah penting bagi industri tersebut untuk membangun trust (kepercayaan) dan komitmen, memiliki rentang waktu yang panjang dan memfasilitasikan pertukaran informasi tersebut jika sebuah hubungan akan dijadikan sasaran akhir. Penekanan yang penting terhadap peningkatan dan kualitas pelayanan (service quality) lebih lanjut disebut sebagai sebuah elemen yang esensial dalam relationship marketing (Christopher, dkk. 1991).

\section{c. Relationalism}

Menurut Hausman (2001 : 604) :

"The rationalism construct is relatively new to the literature and has been operationalized differently in recent studies. Relationalism is used to reflect the normative belief, held by relational partners, that interfirm relationships are valuable and important to survival and success of organization (Boyle et.al., 1992; Kaufmann and Dant, 1996)..."

Dari pendapat di atas dapat dilihat bahwa, konstruk relationalism adalah relatif baru di dalam literatur dan telah dioperasionaliasikan secara berbeda pada sejumlah studi. Relationalism digunakan untuk mencerminkan keyakinan normatif, yang diyakini oleh para relational partner, dimana relationship antar perusahaan atau antar perusahaan dengan pelanggan adalah berharga dan penting terhadap kelanggengan dan keberhasilan dari organisasi (Boyle dkk 1992; Kaufmann dan Dant, 1996). Dengan demikian, relational exchange (pertukaran relasional) yang tinggi akan memiliki relationalism yang lebih tinggi, sedangkan transactional exchange akan lebih rendah (Simpson dan Mayo, 1997). Relationship yang lebih kuat diharapkan akan memiliki skor yang lebih tinggi pada relationalism, ketimbang relationship yang lebih lemah.

Menurut Hausman (2001 : 604605) bahwa : "Empircal studies have proposed relationalism as a second-order construct consisting of solidarity, mutuality and flexibility ((Boyle et.al., 1992; Simpson and Mayo, 1997)..." Artinya, studi-studi empiris telah mengajukan relationalism sebagai konstruk urutan kedua yang terdiri atas solidaritas, mutualitas, dan fleksibilitas (Boyle dkk, 1992; Simpson dan Mayo , 1997). Beberapa studi memasukkan durasi sebagai ukuran keempat dari relationalism (Anderson dan Gerbing, 1982; Simpson dan Mayo ,1997).

Menurut Hausman (2001 : 604605) bahwa : "Evidence suggests that, not only does the degree of relationsm vary from one relationship to another, but also relationship characterized by higher level of relationalism produce superior outcomes (impson and Mayo, 1997)". Jadi, bukti menunjukkan bahwa, bukan hanya derajat relationalism yang bervariasi dari satu relationship dengan yang lainnya, tetapi 
relationship juga dicirikan oleh level of relationalism yang lebih tinggi yang menghasilkan outcome yang superior (Simpson dan Mayo, 1997).

\section{Aplikasi Relationship Strength Antara}

\section{Perusahaan dan Pelanggan}

Menurut Pressey dan Mathews (2000 : 5) bahwa :

"The practice of relationship marketing is most applicable when the following conditions exist : There is an ongoing desire for the part of theservice customer; The customer controls selection of the service supplier; There alternative service suppliers, with customers switching from one to another being common (Berry, 1983)”.

Dari pendapat di atas dapat dilihat bahwa, praktek relationship dalam pemasaran dapat diaplikasikan bilamana ada sejumlah kondisi sebagai berikut : 1) Terdapat keinginan yang berkelanjutan untuk menggunakan service pada sisi pelanggan (customer); 2) Mengendalikan pemilihan atas service supplier; 3) Terdapat sejumlah service suppliers alternatif, dengan customers yang saling melakukan perpindahan dari satu service supplier yang satu ke yang lainnya.

Dalam membentuk program relationship dalam pemasaran menurut Kotler (1996 : 905), diperlukan langkahlangkah utama sebagai berikut :

“1) Identify the Key Customers Meriting Relationship Marketing; 2) Assign a Skilled Relationship Manager to Each Key Customer; 3) Develop a Clear Job Description for Relationship Managers; 4) Appoint an Overall Manager to Supervise the Relationship Managers; and 5) Each the Relationship Manager Must Develop Long-Range and Annual CustomerRelationship Plans."

Artinya, langkah-langkah utama dalam membentuk program relationship dalam pemasaran adalah Mengidentifikasi pelanggan-pelanggan kunci yang sesuai dengan Relationship Marketing; 2) Menugaskan seorang Relationship Managers yang ahli untuk tiap pelanggan kunci; 3) Membuat Job Description for Relationship Managers; 4) Menunjuk seorang Overall Manajer untuk mengawasai Relationship Managers; dan 5) Tiap Relationship Manager harus membuat rencana Customer-Relationship Plans Jangka Panjang dan Tahunan.

Menurut Pressey dan Mathews (2000 : 3) bahwa :

"The more personal the service the greater the inclination toward increase communication, thus, giving a higher potential for the use of relationship marketing. Gummesson (1994) compiled a list of some 30 relationship types, his sixteenth relationship type "personal and social networks" he claims " often determine the business networks. In some cultures, even, business is solely conducted between friends and friends-of-friends." 
Dari pendapat di atas, dapat diketahui bahwa, semakin personal sifat dari suatu service (jasa) maka semakin besar kecenderungan menuju meningkatnya komunikasi, sehingga memberikan potensi yang lebih besar untuk menggunakan relationship marketing. Gumesson (1994) menggabungkan sejumlah daftar yang berisikan 30 jenis relationship dan 16 jenis diantaranya merupakan hubungan yang berjenis "personal and social network" ia mengklaimnya sebagai business network atau jaringan bisnis.

Pressey dan Mathews (2000 : 3) selanjutnya mengatakan bahwa : "Personal involvement can be seen as being of great importance in services marketing (and Relationship Marketing in general) allowing interaction between both parties to take place in the service delivery process." Artinya keterlibatan personal dapat dipandang sebagai hal yang penting dalam services marketing dan relationship marketing secara umum, sehingga memudahkan adanya interaksi antar kedua belah pihak untuk turut serta dalam proses service delivery.

Sebuah perspektif yang lebih lanjut disajikan oleh Perrien dkk. (1995 : 323), mereka berpendapat bahwa peran dari orang-orang yang berada di lini depan (front-line people) adalah sebuah isu yang utama yang harus dipertimbangkan agar mencegah rusaknya hubungan customer yang sudah baik. Dengan demikian, menurut Pressey dan Mathews (2000:3) : "Personal service also facilities customer retention." Artinya personal service (pelayanan secara pribadi) juga memperlancar usaha mempertahankan pelanggan (customer retention).

Menurut Pressey dan Mathews (2000 : 3) bahwa : "Successful marketing relationship involve co-operative partners, not power-conscious adversaries..." Jadi, menurut Pressey dan Mathews, bahwa hubungan pemasaran yang berhasil mengakibatkan mitra usaha yang kooperatif, bukan pesaing yang merasa kuat (power-conscious adversaries). Relationship biasanya membutuhkan mutual co-operation (kerjasama yang saling bahu membahu) atau partnership (kemitraan) dari pada sekedar mendominasi salah satu pihak. Disamping itu juga membutuhkan profesionalisme yang tinggi.

Dalam hal professionalism ini Pressey dan Mathews (2000 : 3) mempunyai proposisi (proposition) bahwa : "Services with a high degree of professionalism involved within the service episode facilitate the condition for relationship marketing." Artinya service dengan tingkat profesionalisme yang tinggi yang terlibat dalam episode service dapat mempermudah terjadinya kondisi-kondisi yang menguntungkan bagi relationship marketing.

Hal lain yang sangat perlu mendapat perhatian dalam aplikasi 
relationship strength adalah involvement (keterlibatan) yaitu merupakan hubungan interaktif antara customer dengan pihak perusahaan. Lebih lanjut menurut pendapat Pressey dan Mathews (2000 : 3) bahwa : "An increase in customer involvement (psychological, rather than just activity based) can be seen as an axiom for relationship marketing. Artinya, peningkatan dalam melibatkan customer (yang bersifat psikologis, daripada sekedar berbasis aktifitas) dapat dipandang sebagai aksioma bagi relationship dalam pemasaran sehingga terjalin kekuatan hubungan (relationship strength) antara perusahaan dengan pelanggan (customers).

5. Mempertahankan Pelanggan Dengan Memberikan Kepuasan (Customer Satisfaction)

$\begin{array}{rrr} & \text { Pelanggan adalah semua orang } \\ \text { yang menuntut perusahaan untuk }\end{array}$ memenuhi standar kualitas tertentu yang akan memberikan pengaruh pada performansi perusahaan. Pelanggan (customer) bisa individu atau organisasi yang secara aktual membuat sebuah keputusan pembelian, sedangkan consumer (konsumen) adalah individu atau organisasi unit yang menggunakan atau mengkonsumsi sebuah produk.

Menurut Gaspersz (1997 : 8) :

"Ada beberapa definisi pelanggan yaitu : a) Pelanggan adalah orang yang tidak tergantung pada kita, tetapi kitalah yang tergantung padanya; b) Pelanggan adalah orang yang membantu kita kepada keinginannya; c) Tidak ada seorangpun yang pernah menang beradu argumentasi dengan pelanggan; d) Pelanggan adalah orang yang teramat penting yang harus dipuaskan."

Dewasa ini banyak perusahaan berusaha sekuat tenaga mempertahankan pelanggannya. Mereka sadar bahwa biaya menarik satu pelanggan baru bisa lima kali dari biaya mempertahankan pelanggan yang ada. Sayang sekali sistem akuntansi perusahaan gagal menunjukan nilai dari pelanggan setia (Kotler, 2000 : 54). Jelas perusahaan ini mengeluarkan lebih banyak biaya untuk menarik pelanggan baru daripada nilai pelanggan sebenarnya. Pelanggan adalah asset yang sangat berharga bagi perusahaan.

Menurut pendapat Griffin (1995 :

4) bahwa :

"Customer retention describes the length of relationship with a customer. A customer retention rate is the percentage of customers who have meet a specified number of repurchases over a finite period of time. A firm's share of customer denotes the percentage of a customer's budget spent with the firm".

Jadi, customer retention menggambarkan lamanya hubungan dengan pelanggan. Tingkat customer retention sendiri merupakan persentase pelanggan 
yang telah mencapai sejumlah tingkat pembelian ulang atas produk suatu perusahaan. Sedangkan nilai belanja pelanggan merupakan persentase budget pelanggan yang disediakan untuk membeli produk perusahaan.

Menurut Kotler (2000 : 49) bahwa :

"There are two ways to strengthen customer retention. One is to erect high switching barriers. Customers are less inclined to switch to another supplier when this would involve high capital cost, high search cost, the loss of loyal-customer discounts."

Jadi karena mempertahankan pelanggan menurut Kotler adalah yang paling utama, maka ada dua cara untuk mempertahankannnya. Salah satu, adalah menyulitkan pembeli untuk berganti pemasok. Pelanggan cenderung tidak berganti pemasok, kalau biaya modalnya tinggi, biaya pencariannya tinggi, dan diskon sebagai pelanggan setianya hilang.

Kotler berpendapat (2000: 49) bahwa :

"The better approach is to deliver high customers satisfaction. This make it harder for a competitor to overcome barriers by simply offering lower prices or switching inducments. The task of creating strong customer loyalty is called relationship marketing."

Dari pendapat Kotler di atas, pendekatan yang lebih baik untuk mempertahankan pelanggan adalah dengan memberikan kepuasan pelanggan yang tinggi, sehingga pelanggan akan lebih sulit bagi saingannya untuk menerobos halangan (barriers) dengan menawarkan harga lebih murah atau rangsangan lain. Kepuasan pelanggan sesudah pembelian tergantung dari kinerja penawaran dibanding dengan harapannya. Berikut ini definisi tentang kepuasan pelanggan adalah : "Satisfaction is a person's feelings of pleasure or disappointment resulting from comparing a product's perceived performance (or outcome) in relation to his or her expectations" (Kotler, 2000 : 36).

Jadi kepuasan adalah tingkat perasaan kesenangan atau kekecewaan seseorang setelah membandingkan kinerja (atau hasil) yang dia rasakan dibandingkan dengan harapannya. Jadi tingkat kepuasan adalah fungsi dari perbedaan antara kinerja yang dirasakan dengan harapan. Pelanggan dapat mengalami salah satu dari tiga tingkat kepuasan yang umum berlaku. Misalnya kalau kinerja dibawah harapan, pelanggan kecewa; kalau kinerja sesuai harapan, pelanggan puas; dan kalau kinerja melebihi harapan, pelanggan sangat puas, senang atau gembira.

Menurut Kotler (2000 : 48) bahwa :

"The key to customer retention is customer satisfaction. A highly satisfied customer : Stays loyal longer; Buys more as the company introduces new products and upgrades existings product; Talks favorably about the company and its products; Pays 
less attention to competing brands and advertising and is less sensitive to price; Offers product or services ideas to the company; Costs less to serve than new costumers because transactions are routinized."

Dari pendapat di atas, ternyata kunci mempertahankan pelanggan adalah kepuasan pelanggan. Dengan kata lain, tujuan memberikan kepuasan kepada pelanggan adalah untuk mempertahankannya. Seorang pelanggan yang sangat puas maka : (a) Pelanggan akan membeli lebih banyak produk dan akan setia pada produk tersebut lebih lama; (b) Pelanggan akan membeli jenis produk baru atau produk yang disempurnakan oleh perusahaan; (c) Pelanggan memuji-muji perusahaan dan produknya pada orang lain; (d) Pelanggan akan kurang memperhatikan merek dan iklan dari pesaing dan kurang memperhatikan harganya; (e) Pelanggan akan menawarkan gagasan barang dan jasa kepada perusahaan; dan (f) Lebih murah biaya pelayanannya daripada pelanggan baru, karena transaksinya sudah rutin. Dengan puasnya pelanggan diharapkan agar mereka akan semakin setia kepada produk maupun perusahaan yang memproduksi produk itu.

\section{Pengaruh Relationship Strength}

Dengan Kepuasan Pelanggan

(Customer Satisfaction)
Perusahaan dapat mengembangkan hubungan yang kuat (relationship strength) dengan pelanggan, sehingga pelanggan mendapat kepuasan. Konsep dari relationship strength menambah pemahaman baru tentang apa yang membuat suatu relationship atau hubungan berhasil, dengan menunjukkan bahwa keberhasilan tersebut dapat dihasilkan dari sebuah kombinasi dari sejumlah faktor kompensasi, ketimbang dari sebuah faktor tunggal. Dengan demikian, kepercayaan (trust), komitmen (commitment) dan relationalisme dapat dikombinasikan untuk menghasilkan outcome yang diinginkan. Hal ini dikatakan oleh Hausman (2001 : 610) : "Thus, trust, commitment, and rationalism combine to produce desired outcome”. Selanjutnya menurut Hausman (2001 : 610) : "The relationship contruct also suggest how relationships might be managed most efficiently for maximum returns". Artinya, konstruk relationship strength juga menunjukkan bagaimana sejumlah relationships dapat dikelola dengan cara yang paling efisien untuk menghasilkan returns yang maksimal.

Menurut Foster dand Cadogan (2000 : 186) bahwa : “... trust in a salesperson is establish as an antecedent to satisfaction with the salesperson." Artinya kepercayaan kepada penjual dibentuk sebagai antecedent bagi kepuasan dengan penjual. Jika pelanggan merasa bahwa penjual itu setia, jujur, dan percaya bahwa 
tindakan penjual akan memberikan hasil positif, pelanggan cenderung untuk merasa sangat puas (Geyskens et.el., 1998). Pengalaman positif dari interaksi pembelipenjual dan adanya customers' trust menyebabkan melanjutkan hubungan baik.

Foster dan Cadogan (2000 : 188) juga berpendapat bahwa : “A customer's interaction with the firm will likely involve dealings with both the salesperson and other service employees..." Artinya, interaksi pelanggan dengan perusahaan cenderung melibatkan hubungan penjual dengan karyawannya dan kepuasan dengan penjual hanyalah satu aspek yang mempengaruhi kepuasan pelanggan dengan perusahaan (Snyder, 1998; Berry and Parasuraman, 1992).

Bukan hanya para karyawan dari perusahaan yang merasa lebih puas (satisfaction) dengan relationship bilamana mereka mempersepsikan adanya sebuah relationship yang kuat, namun mereka dapat menilai performance dari perusahaan dengan lebih tinggi. Hal ini menunjukkan bahwa perusahaan akan memperoleh manfaat dengan mendorong terjalinnya relationship yang lebih kuat dengan para pelanggan seperti kepuasan pelanggan (customers satisfaction), termasuk semakin meningkatkan ketergantungan atas sejumlah strategi yang kooperatif dan relationship yang tidak begitu merugikan (Hausman, 2001 : 610-611).
Menurut Hausman (2001 : 602) : "The benefits of stronger relationships do not end with satisfaction and performance improvements, importans as these outcomes are, but extend to other strateies necessary for growth and survival of business". Jadi, berbagai benefit terhadap relationships yang lebih kuat tidak berakhir dengan kepuasan dan peningkatan performance saja, yang tak kalah penting dengan outcome ini, namun juga diperluas untuk sejumlah strategi yang dibutuhkan untuk pertumbuhan dan kelangsungan atas bisnis.

$$
\text { Hausman (2001 : 602) juga }
$$
berpendapat bahwa :

"The outcome of a successful relationship can be expressed in terms of cooperation and adaptability, quality of performance, satisfaction and durability of liaison. The key to success lies in a combination of trust, commitment and relational orientation on either side. These, together, are significant contributors to successful relationship building, helping business survive internal external challenges that may threaten the relationship, and offsetting the impact of any conflicting needs or goals".

Dari pendapat di atas dapat diartikan bahwa, outcome dari sebuah relationships yang berhasil dapat diekspresikan dalam hal kerjasama dan adaptability, kualitas dari performance, satisfaction (kepuasan) dan durability (lamanya) hubungan tersebut. Kunci keberhasilannya terletak pada kombinasi dari trust, komitmen dan 
orientasi hubungan pada kedua sisi.

Kesemua ini merupakan kontributor yang signifikan terhadap penjalinan relationships yang berhasil, membantu bisnis dapat bertahan dalam menghadapi sejumlah tantangan internal dan external yang dapat mengancam relationships yang mereka miliki, dan menutupi dampak dari setiap kebutuhan atau tujuan yang bertentangan.

Jika perusahaan beralih dari
pandangan berwawasan transaksi ke
kuat (relationship strenght), mereka akan menciptakan program untuk membuat pelanggannya datang kembali, membeli lebih banyak dan menjadi pelanggan yang tetap setia (customers' loyalty). Tantangannya adalah menciptakan hubungan khusus dengan "pelanggan terbaik" (the best customers) dari perusahaan dimana pelanggan merasakan komunikasi dua arah yang baik dan merasa mendapat hak serta hadiah khusus.

Dari uraian tersebut di atas, dapat dibuat skema kerangka pemikirannya sebagai berikut : 


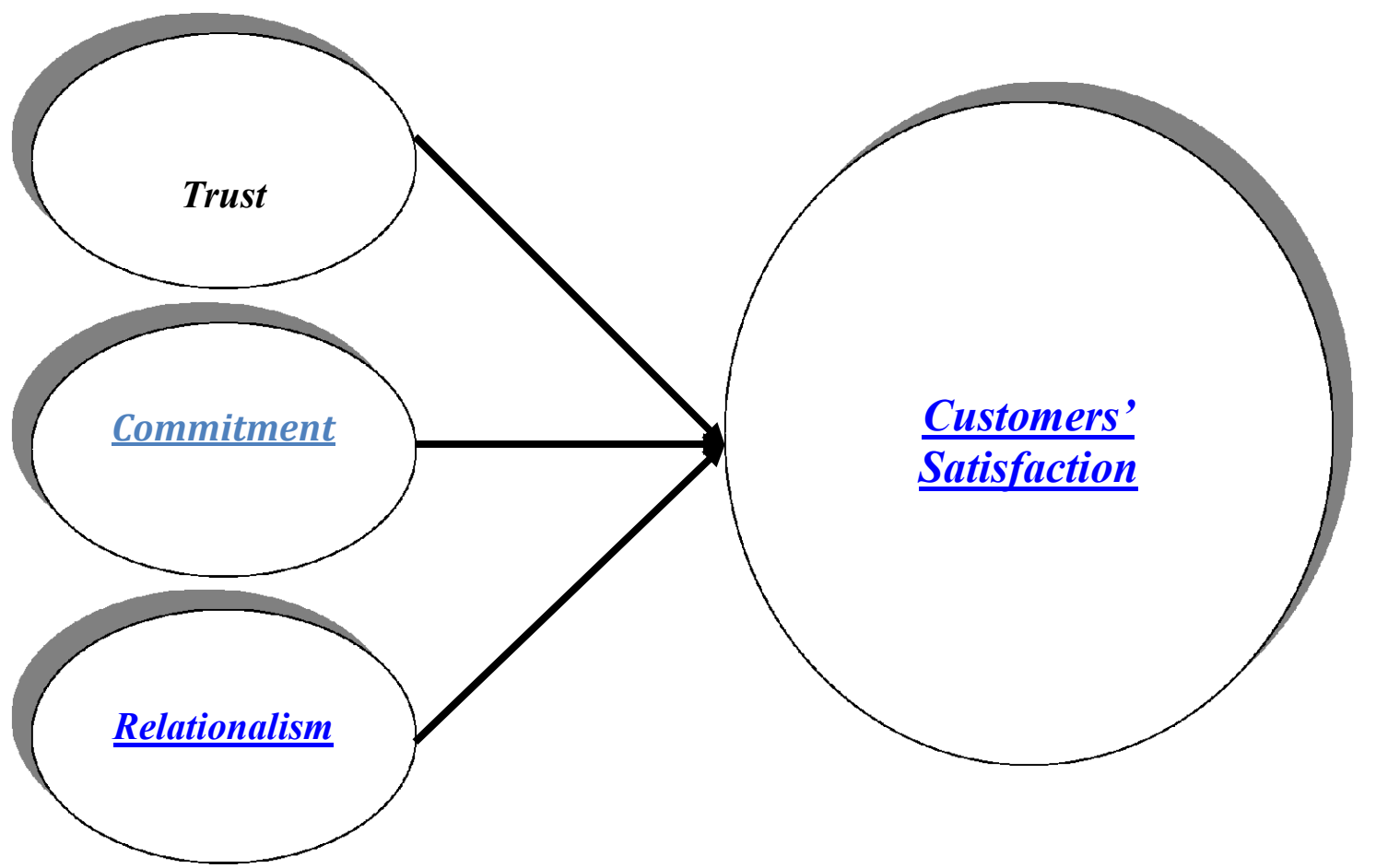

Gambar

Skema Kerangka Pemikiran

Tanggapan Responden Terhadap Berbagai Variasi Dalam

Relationship Strength dan Customers' Satisfaction

Pada Maskapai Penerbangan (Airlines)

Sesuai dengan hasil penelitian yang ada didalam Journal of Business \& Industrial Marketing (Hausman, 2001 : 603) yang digunakan sebagai acuan penelitian ini seperti telah diuraikan di muka, maka relationship strength yang diteliti terdiri dari tiga variasi atau dimensi yaitu : kepercayaan (trust), komitmen (commitment) dan relationalism. Kemudian telah disebutkan juga bahwa untuk skala pengukuran yang digunakan dalam penelitian ini, diukur dengan Skala Likert, dengan skala mulai dari $1=$ Sangat Tidak Setuju, $2=$ Tidak Setuju, $3=$ Agak Tidak Setuju, $4=$ Ragu-ragu/Netral, $5=$ Agak Setuju, $\quad 6=$ Setuju, dan $7=$ Sangat Setuju . Berdasarkan descriptive statistics hasil pengolahan data yang diperoleh dari tanggapan responden terhadap kepercayaan (trust), komitmen (commitment), relationalism dan customers' satisfaction pada maskapai penerbangan (airline) seperti tercantum dalam Tabel. 
Tabel .

Descriptive Statistics Tanggapan Responden Terhadap

Variasi atau Dimensi Dalam Relationship Strength

$$
(\mathrm{n}=398)
$$

\begin{tabular}{|c|l|c|c|}
\hline No. & \multicolumn{1}{|c|}{ Dimensi } & $\begin{array}{c}\text { Skor rata-rata } \\
(\text { Mean })\end{array}$ & $\begin{array}{c}\text { Standard } \\
\text { Deviation }\end{array}$ \\
\hline 1. & Dimensi-Dimensi Relationship Strength & 6.3695 & 0.4893 \\
\hline & a. Kepercayaan (trust) & 6.3967 & 0.5994 \\
\hline & b. Komitmen (commitment) & 6.3739 & 0.4516 \\
\hline & c. Relationalism & & \\
\hline 2. & Cutomers 'Satisfaction & 6.3379 & 0.4484 \\
\hline
\end{tabular}

Sumber : Penelitian 
Dari Tabel di atas, dapat dijelaskan hasil skor rata-rata (mean) dari tanggapan responden terhadap dimensi-dimensi dalam relationship strength dan customers' satisfaction sebagai berikut : Berbagai Variasi atau Dimensi Dalam Relationship Strength Pada Maskapai Penerbangan (Airlines)Pada Tabel di atas, dapat dilihat berbagai variasi atau dimensi dalam relationship strength yang terdiri dari tiga dimensi yaitu : kepercayaan (trust), komitmen (commitment) dan relationalism.

Secara keseluruhan untuk variasi atau dimensi dalam relationship strength ini memiliki skor mean sebesar 6.3695 dengan standard deviation sebesar 0,4893. Hal ini menunjukkan bahwa jawaban responden terhadap variabel relationship strength ini berkisar antara setuju sampai dengan sangat setuju. Hal ini berarti dimensi dalam relationship strength sangat diperhatikan oleh responden dalam rangka menjalin hubungan yang kuat dengan maskapai penerbangan langganannya. Jika diperhatikan lebih rinci, maka pada setiap dimensi dari ketiga dimensi yang membentuk relationship strength dapat dilihat dalam uraian sebagai berikut :

\section{a. Kepercayaan (Trust)}

Jawaban responden terhadap kepercayaan (trust), rata-ratanya (mean) sebesar 6.3967 dengan standard deviation sebesar 0,5994. Artinya jawaban responden terhadap kepercayaan (trust) dalam menjalin hubungan dengan maskapai penerbangan berkisar antara setuju sampai dengan sangat setuju. Hal ini menunjukkan betapa pentingnya bagi pelanggan tentang kepercayaan (trust) agar terjalin hubungan yang kuat dan baik.

\section{b. Komitmen (Commitment)}

Pada Tabel di atas dapat juga dilihat bahwa komitmen (commitment) dengan skor mean sebesar 6.3739 dengan standard deviation sebesar 0,4516. Keadaan ini menunjukkan bahwa jawaban responden terhadap komitmen (commitment) berkisar antara setuju sampai dengan sangat setuju. Hal ini juga berarti bagi responden, komitmen (commitment) terhadap maskapai penerbangan sangat tinggi dan sangat penting dalam menjalin hubungan yang kuat dengan maskapai penerbangan langganan mereka.

\section{c. Relationalism}

Pada Tabel di atas dapat juga dilihat bahwa relationalism dengan skor mean sebesar 6.3379 dengan standard deviation sebesar 0,4484 . Hal ini juga menunjukkan bahwa jawaban responden terhadap relationalism berkisar antara setuju sampai dengan sangat setuju. Keadaan ini menunjukkan bahwa 
relationalism yang mencerminkan keyakinan normatif yang diyakini oleh para relational partner antara pelanggan dengan maskapai penerbangan sangat berharga dan penting terhadap kelanggengan dan keberhasilan dari hubungan yang kuat. Artinya dalam menjalin hubungan yang kuat (relationship strength) diperlukan relationalism atau norma-norma yang baik yang dapat mendukung terjalinnya suatu hubungan yang kuat antara pelanggan dengan maskapai penerbangan.

\section{Customers' Satisfaction}

Pada Tabel di atas, dapat dilihat customers' satisfaction memiliki skor mean sebesar 6.3588 dengan standard deviation sebesar 0,5449. Hal ini menunjukkan bahwa jawaban responden terhadap variabel customers' satisfaction ini berkisar antara setuju sampai dengan sangat setuju. Dengan demikian variabel customers' satisfaction sangat diperhatikan oleh responden dalam rangka menjalin hubungan yang kuat dengan maskapai penerbangan langganannya. Responden sangat setuju dengan adanya kepuasan (customers' satisfaction) dalam suatu hubungan yang terjalin antara pelanggan dengan maskapai penerbangan. Dengan adanya rasa percaya (trust), komitmen (commitment), dan relationalism dalam menjalin hubungan yang kuat (relationship strength) dengan maskapai penerbangan, tampak dari jawaban responden, mereka menginginkan kepuasan (customers' satisfaction).

Dari jawaban responden dapat diketahui bahwa dengan adanya ikatan dan jalinan hubungan yang kuat (relationship strength) yang tercermin dalam trust, commitment, dan relationalism antara pelanggan dengan maskapai penerbangan seperti tersebut di atas, membuat mereka merasa puas dan mau bertahan terus menjadi pelanggan (customers retention) maskapai penerbangan tersebut.

Pengujian Hipotesis Tentang Berbagai Variasi Dalam

\section{Relationship Strength Dengan Customers'}

\section{Satisfaction}

\section{Pada Maskapai Penerbangan (Airlines)}

Hipotesis yang diajukan dimuka, ada 3 hipotesis dan berikut ini dapat diikuti pengujian hipotesis-hipotesis tersebut yaitu sebagai berikut :

\section{Hipotesis Pertama (Ha1)}

Hipotesis Pertama (Ha1) : Terdapat hubungan kepercayaan (trust) dengan kepuasan pelanggan (customers' satisfaction) Selanjutnya lihat Tabel $4.11 \mathrm{di}$ bawah ini. 
Tabel

Pearson Correlation Antara Kepercayaan (Trust) Dengan Customers' Satisfaction

\begin{tabular}{|l|l|c|}
\hline \multicolumn{2}{|c|}{ _U r a i a n } & Customers' Satisfaction \\
\hline Kepercayaan & Pearson Correlation & $0.876^{*}$ \\
(Trust) & Sig. (2-tailed) & 0.000 \\
& N & 398 \\
\hline
\end{tabular}

* The correlation significant at the 0.05 level (2-tailed).

Sumber : Hasil print-out SPSS/PC .

Pada Tabel di atas, dapat dilihat nilai Pearson Correlation antara dimensi kepercayaan (trust) dengan kepuasan pelanggan (customers' satisfaction) dengan nilai $\mathrm{r}=0.876$. hubungan ini bertanda positif dan tergolong high correlation (karena berada diantara $0.80-1.00$ ) serta signifikan pada level of significant 0.05 $($ sig. $=0.000)$. Hal ini menunjukkan bahwa Hol gagal diterima dan Hal tersebut di atas dapat diterima.

Dengan demikian terdapat hubungan yang positip antara kepercayaan (trust) dengan kepuasan pelanggan (customers' satisfaction). Dari hubunganyang positif ini dapat dikatakan bahwa jika kepercayaan (trust) semakin tinggi, kepuasan pelanggan (customers' satisfaction) juga akan naik. Berarti maskapai penerbangan tersebut harus menjaga hubungan baik dengan pelanggan dan meningkatkan kepercayaan (trust) pelanggan terhadap karyawan/pramugari maskapai penerbangan tersebut.

\section{Hipotesis Kedua (Ha2)}

Hipotesis Kedua (Ha2): Terdapat hubungankomitment (commitment) dengan terhadap kepuasan pelanggan (customers' satisfaction). Selanjutnya lihat Tabel dibawah ini.

Tabel

Pearson Correlation Antara Komitmen

(Commitment)

Dengan Customers' Satisfaction

\begin{tabular}{|l|l|c|}
\hline \multicolumn{2}{|c|}{ U r a i a n } & $\begin{array}{c}\text { Customers' } \\
\text { Satisfaction }\end{array}$ \\
\hline $\begin{array}{l}\text { Komitmen } \\
\text { (Commitment) }\end{array}$ & Pearson & $0.805^{*}$ \\
& Correlation & 0.000 \\
& Sig. (2-tailed) & 398 \\
\hline
\end{tabular}

* The correlation significant at the 0.05 level (2-tailed).

Sumber : Hasil print-out SPSS/PC ${ }^{+}$.

Pada Tabel di atas, dapat dilihat nilai Pearson Correlation antara dimensi komitmen (commitment) dengan kepuasan pelanggan (customers' satisfaction) dengan nilai $\mathrm{r}=0.805$. Hubunganini bertanda positif dan tergolong high correlation (karena berada diantara $0.80-1.00$ ) serta signifikan pada level of significant 0.05 $($ sig. $=0.000)$. Hal ini menunjukkan bahwa Ho1 gagal diterima dan Ha1 tersebut di atas dapat diterima. 
Dengan demikian terdapat hubunganyang positip antara komitmen (commitment) dengan kepuasan pelanggan (customers'satisfaction). Hal ini dapat pula diartikan bahwa semakin tinggi komitmen (commitment) pelanggan terhadap maskapi penerbangan itu, maka semakin tinggi pula kepuasan pelanggan (customers' satisfaction). Jadi, dalam menjalin hubungan yang kuat antara pelanggan dengan maskapai penerbangan, perlu ditingkatkan komitmen (commitment) pelanggan terhadap maskapi penerbangan tersebut.

\section{Hipotesis Ketiga (Ha3)}

Hipotesis Ketiga (Ha3) : Terdapat hubunganrelationalism dengan kepuasan pelanggan (customers' satisfaction). Selanjutnya lihat Tabel

\section{Tabel}

Pearson Correlation Antara

Relationalism

Dengan Customers'Satisfaction

\begin{tabular}{|l|l|c|}
\hline \multicolumn{2}{|c|}{ U r a i a n } & $\begin{array}{l}\text { Customers } \\
\text { Satisfaction }\end{array}$ \\
\hline $\begin{array}{l}\text { Relationali } \\
\text { sm }\end{array}$ & $\begin{array}{l}\text { Pearson } \\
\text { Correlatio } \\
\text { n Sig. (2- } \\
\text { tailed) } \\
\mathrm{n}\end{array}$ & $0.810^{*}$ \\
\hline
\end{tabular}

* The correlation significant at the 0.05 level (2-tailed).

Sumber : Hasil print-out SPSS/PC

Pada Tabel di atas, dapat dilihat nilai Pearson Correlation antara dimensi relationalism dengan kepuasan pelanggan (customers' satisfaction) dengan nilai $\mathrm{r}=$ 0.810. Hubunganini bertanda positif dan tergolong high correlation (karena berada diantara 0.80 - 1.00) serta signifikan pada level of significant 0.05 (sig. = 0.000). Hal ini menunjukkan bahwa Hol gagal diterima dan Hal tersebut di atas dapat diterima.

Dengan demikian, terdapat hubunganyang positip antara relationalism dengan kepuasan pelanggan (customers' satisfaction). Jadi dapat dikatakan bahwa jika relationalism naik, maka kepuasan pelanggan (customers' satisfaction) juga akan naik. Berarti antara pelanggan dengan maskapai penerbangan tersebut dalam rangka menjalin hubungan yang kuat antara pelanggan dengan maskapai penerbangan, maka harus ditingkatkan relationalism baik di pihak pelanggan maupun pihak maskapai penerbangan tersebut.

\section{HubunganAntara Relationship Strength Dengan Customers' Satisfaction \\ Pada Maskapai Penerbangan (Airline)}

Hubungan antara berbagai variasi atau dimensi-dimensi yang membentuk relationship strength dengan kepuasan pelanggan (customers' satisfaction) secara keseluruhan dapat dilihat dalam Tabel di bawah ini. 
Tabel

Pearson Correlation Antara Relationship Strength

Dengan Customers' Satisfaction

\begin{tabular}{|l|l|c|}
\hline \multicolumn{2}{|c|}{ U r a i a n } & $\begin{array}{c}\text { Customers' } \\
\text { Satisfaction }\end{array}$ \\
\hline $\begin{array}{l}\text { Relationsh } \\
\text { ip } \\
\text { Strength }\end{array}$ & $\begin{array}{l}\text { Pearson } \\
\text { Correlati } \\
\text { on } \\
\text { Sig. (2- } \\
\text { tailed) } \\
\text { n }\end{array}$ & $0.853^{*}$ \\
& $\begin{array}{l}\text { Salo } \\
398\end{array}$ \\
\hline
\end{tabular}

* The correlation significant at the 0.05 level (2-tailed).

Sumber : Hasil print-out SPSS/PC ${ }^{+}$.

Pada Tabel di atas dapat dilihat bahwa secara keseluruhan hubunganantara relationship strength dengan kepuasan pelanggan (customers' satisfaction), dengan nilai $\mathrm{r}=0.853$. hubunganini bertanda positif dan tergolong high correlation (karena berada diantara $0.80-1.00)$ serta signifikan pada level of significant 0.05 $($ sig. $=0.000)$. Dengan demikian jika relationship strength naik dalam arti jika hubunganantara pelanggan dengan maskapai penerbangan semakin kuat, maka kepuasan pelanggan (customers' satisfaction) juga akan naik. Sebaliknya, jika relationship strength turun dalam arti jika hubunganantara pelanggan dengan maskapai penerbangan semakin lemah, maka kepuasan pelanggan (customers' satisfaction) juga akan turun atau berkurang.

Berarti jalin hubungan yang kuat antara pelanggan dengan maskapai penerbangan (relationship strength) dapat digunakan sebagai salah satu pedoman untuk menyusun strategi meningkatkan kepuasan pelanggan (customers' satisfaction).

Regression Statistics Hasil Penelitian

Regression Statistics dari hasil penelitian ini, selanjutnya dapat dilihat dari hasil pengolahan data dengan multiple regression dalam Tabel di bawah ini.

Tabel

Regression Statistics and Coefficients Dimensi-Dimensi

Relationship Strength dan Customers' Satisfaction

\begin{tabular}{|c|l|c|c|c|}
\hline $\begin{array}{c}\text { Dependent } \\
\text { Variable }\end{array}$ & $\begin{array}{c}\text { Independent } \\
\text { Variable }\end{array}$ & $\begin{array}{c}\text { Standard } \\
\text { ized } \\
\text { Beta }\end{array}$ & $\begin{array}{c}\text { Significa } \\
\text { nce }\end{array}$ & $\begin{array}{c}\text { Adjus } \\
\text { ted } \\
\boldsymbol{R}^{2}\end{array}$ \\
\hline $\begin{array}{l}\text { Customers' } \\
\text { Satisfaction }\end{array}$ & $\begin{array}{l}\text { Dimensi dimensi } \\
\text { Relationship } \\
\text { Strength }\end{array}$ & 0.853 & 0.000 & 0.72 \\
& $\begin{array}{l}\text { a. Kepercayaan } \\
\text { (trust) }\end{array}$ & 0.554 & 0.000 & \\
\cline { 2 - 5 } & $\begin{array}{l}\text { b. Komitmen } \\
\text { (commitment) }\end{array}$ & 0.283 & 0.001 & \\
\cline { 2 - 5 } & $\begin{array}{l}\text { c. Relationalism } \\
\end{array}$ & 0.459 & 0.000 & \\
\hline
\end{tabular}

Sumber : Hasil print-out SPSS/PC ${ }^{+}$ 
Pada Tabel dapat dilihat Regression Statistics and Coefficients dari dimensi-dimensi Relationship Strength dan Customers' Satisfaction dengan penjelasan sebagai berikut :

1. Antara kepercayaan (trust) dengan kepuasan pelanggan (customers' satisfaction), dari hasil penelitian diperoleh Standardized Beta $=0.554$ dan signifikan pada level of significance 0.05 . Hal ini menunjukkan bahwa dalam penelitian ini, kepercayaan (trust) mempunyai pengaruh yang sangat besar terhadap kepuasan pelanggan (customers' satisfaction).

2. Antara komitmen (commitment) dengan kepuasan pelanggan (customers' satisfaction), dari hasil penelitian diperoleh Standardized Beta $=0.283$ dan signifikan pada level of significance 0.05 . Hal ini juga menunjukkan bahwa komitmen (commitment) mempunyai pengaruh terhadap kepuasan pelanggan (customers' satisfaction).

3. Antara relationalism dengan kepuasan pelanggan (customers' satisfaction), diperoleh Standardized Beta $=0.459$ dan signifikan pada level of significance 0.05 . Hal ini juga menunjukkan bahwa relationalism mempunyai pengaruh terhadap kepuasan pelanggan (customers' satisfaction).
4. Dari ketiga dimensi relationship strength di atas, maka yang paling tinggi pengaruhnya terhadap kepuasan pelanggan (customers' satisfaction) adalah kepercayaan (trust) pelanggan terhadap maskapai penerbangan tersebut.

5. Secara keseluruhan dapat pula dinyatakan, berdasarkan Tabel 4.15 bahwa terdapat pengaruh Relationship Strength terhadap Customers' Satisfaction dengan Standardized Beta $=0.853$ dan signifikan pada level of significance 0.05 dengan adjusted $R^{2}=0.727$. Hal ini menunjukkan bahwa dalam penelitian ini, ditemukan kontribusi dari Relationship Strength terhadap Customers' Satisfaction ada sebesar 0.727 atau sebesar $72,7 \%$. Kontribusi atau peranan ini sangat tinggi, sehingga jalinan hubungan baik dan kuat (relationship strength) antara pelanggan dengan maskapi penerbangan tidak dapat diabaikan oleh maskapai perebangan tersebut agar pelanggan tetap puas dan agar pelanggan tidak pindah ke maskapai lain (switching) serta mau bertahan menjadi pelanggan (consumers retention). 


\section{KESIMPULAN}

Berdasarkan uraian-uraian yang telah dibahas dimuka, maka dapat ditarik kesimpulan sebagai berikut :

1. Relationship strength yang diteliti dalam studi ini terdiri dari tiga variasi atau dimensi yaitu : kepercayaan (trust), komitmen (commitment), dan relationalism. Berdasarkan descriptive statistics hasil pengolahan data yang diperoleh dari tanggapan responden terhadap kepercayaan (trust), komitmen

(commitment), relationalism, dan customers' satisfaction pada maskapai penerbangan (airlines) dapat disimpulkan bahwa secara keseluruhan untuk variasi atau dimensi dalam relationship strength ini memiliki skor mean sebesar 6.3695 dengan standard deviation sebesar 0,4893. Hal ini menunjukkan bahwa jawaban responden terhadap variabel relationship strength ini berkisar antara setuju sampai dengan sangat setuju. Hal ini berarti dimensi dalam relationship strength sangat diperhatikan oleh responden dalam rangka menjalin hubungan yang kuat dengan maskapai penerbangan langganannya.

2. Setiap variasi atau dimensi yang membentuk relationship strength dapat dilihat bahwa jawaban responden terhadap kepercayaan (trust) dalam menjalin hubungan dengan maskapai penerbangan berkisar antara setuju sampai dengan sangat setuju. Hal ini menunjukkan betapa pentingnya bagi pelanggan tentang kepercayaan (trust) agar terjalin hubungan yang kuat dan baik. Kemudian jawaban responden terhadap komitmen (commitment) berkisar antara setuju sampai dengan sangat setuju. Hal ini juga berarti bagi responden, komitmen (commitment) terhadap maskapai penerbangan sangat tinggi dan sangat penting dalam menjalin hubungan yang kuat dengan maskapai penerbangan langganan. Responden juga menjawab terhadap relationalism berkisar antara setuju sampai dengan sangat setuju. Artinya relationalism yang mencerminkan keyakinan normatif yang diyakini oleh para relational partner antara pelanggan dengan maskapai penerbangan sangat berharga dan penting terhadap kelanggengan dan keberhasilan dari hubungan yang kuat.

3. Kepuasan pelanggan (customers' satisfaction) memiliki skor mean sebesar 6.3588 dengan standard deviation sebesar 0,5449. Hal ini menunjukkan bahwa jawaban responden terhadap variabel customers' satisfaction ini berkisar antara setuju sampai dengan sangat setuju. Dengan demikian variabel customers' satisfaction sangat 
diperhatikan oleh responden dalam rangka menjalin hubungan yang kuat dengan maskapai penerbangan langganannya. Dengan adanya rasa percaya (trust), komitmen (commitment), dan relationalism dalam menjalin hubungan yang kuat (relationship strength) dengan maskapai penerbangan, tampak dari jawaban responden, mereka menginginkan kepuasan (customers' satisfaction).

4. Dari hasil pengujian Hipotesis Pertama (Ha1) dapat dibuktikan bahwa terdapat hubungan yang positif antara kepercayaan (trust) dengan kepuasan pelanggan (customers' satisfaction) dengan nilai Pearson Correlation $(\mathrm{r}=$ 0.876) dan tergolong high correlation serta signifikan pada level of significant 0.05. Dapat dikatakan bahwa jika kepercayaan (trust) semakin tinggi, kepuasan pelanggan (customers' satisfaction) juga akan naik. Berarti maskapai penerbangan tersebut harus menjaga hubugan baik dengan pelanggan dan meningkatkan kepercayaan (trust) pelanggan terhadap karyawan/pramugari maskapai penerbangan tersebut.

5. Hasil uji Hipotesis Kedua (Ha1) juga terbukti bahwa terdapat hubungan yang positif antara komitment (commitment) dengan terhadap kepuasan pelanggan (customers' satisfaction) dengan nilai Pearson Correlation $(\mathrm{r}=0.805)$ dan tergolong high correlation serta signifikan pada level of significant 0.05 . Hal ini dapat pula diartikan bahwa semakin tinggi komitmen (commitment) pelanggan terhadap maskapi penerbangan itu, maka semakin tinggi pula kepuasan pelanggan (customers' satisfaction). Dalam menjalin hubungan yang kuat antara pelanggan dengan maskapai penerbangan, perlu ditingkatkan komitmen (commitment) pelanggan terhadap maskapai penerbangan tersebut.

6. Hipotesis Ketiga (Ha3) juga terbukti bahwa terdapat hubungan yang positif antara relationalism dengan kepuasan pelanggan (customers' satisfaction) dengan nilai Pearson Correlation $(\mathrm{r}=$ 0.810) dan tergolong high correlation serta signifikan pada level of significant 0.05. Dengan demikian, dapat dikatakan bahwa jika relationalism naik, maka kepuasan pelanggan (customers' satisfaction) juga akan naik. Berarti antara pelanggan dengan maskapai penerbangan tersebut dalam rangka menjalin hubungan yang kuat antara pelanggan dengan maskapai penerbangan, maka harus ditingkatkan relationalism baik di pihak pelanggan maupun pihak maskapai penerbangan tersebut. 
7. Hubungan antara berbagai variasi atau dimensi-dimensi yang membentuk relationship strength dengan kepuasan pelanggan (customers' satisfaction) secara keseluruhan sangat kuat dengan nilai $\mathrm{r}=0.853$ dan tergolong high correlation serta signifikan pada level of significant 0.05. Jadi, jika relationship strength naik dalam arti jika hubungan antara pelanggan dengan maskapai penerbangan semakin kuat, maka kepuasan pelanggan (customers' satisfaction) juga akan naik. Sebaliknya, jika jika relationship strength turun dalam arti jika hubungan antara pelanggan dengan maskapai penerbangan semakin lemah, maka kepuasan pelanggan (customers' satisfaction) juga akan turun atau berkurang. Dengan demikian, jalin hubungan yang kuat antara pelanggan dengan maskapai penerbangan (relationship strength) dapat digunakan sebagai salah satu pedoman untuk menyusun strategi meningkatkan kepuasan pelanggan (customers' satisfaction).

8. Secara keseluruhan dapat pula dinyatakan, bahwa terdapat pengaruh Relationship Strength terhadap Customers' Satisfaction dengan Standard Beta $=0.747$ dan signifikan pada level of significance 0.05 dengan adjusted $R^{2}=0.779$. Hal ini berarti, dalam penelitian ini juga ditemukan bahwa kontribusi dari Relationship Strength terhadap Customers' Satisfaction ada sebesar 0.779 atau sebesar 77,9 \%. Kontribusi atau peranan ini sangat tinggi, sehingga jalinan hubungan baik dan kuat (relationship strength) antara pelanggan dengan masakapi penerbangan tidak dapat diabaikan oleh maskapai perebangan tersebut agar pelanggan tetap puas dan agar pelanggan tidak pindah ke maskapai lain (switching) serta mau bertahan menjadi pelanggan (consumers retention). Dari ketiga dimensi relationship strength di atas, maka yang paling tinggi pengaruhnya terhadap kepuasan pelanggan (customers' satisfaction) adalah kepercayaan (trust) pelanggan terhadap maskapai penerbangan tersebut.

\section{DAFTAR PUSTAKA}

Cooper, R. Donald and Schindler, Pamela S. Business Research Methods. Sixth Edition, Boston : McGraw-Hill International Edition, 1998.

Engel, James F., et. al. Consumer Behavior. Eighth Edition. Orlando, USA : The Dryden Press, Inc., 1995.

Foster, Brian D. and John W. Cadogan. Relationship Selling and Customer Loyalty : An Empirical 
Investigation dalam Marketing Intelligence Journal. Wellington : MCB University Press, 2000.

Griffin, Jill. Customer Loyalty : How to Earn It, How to Keep It. Lexington Book, 1995.

Gaspersz, Vincent. Manajemen Kualitas Penerapan Konsep-Konsep Kualitas Dalam Manajemen Bisnis Total. Jakarta : Yayasan Indonesia Emas dan Penerbit PT. Gramedia Pustaka Utama, Jakarta, 1997.

Gaspersz, Vincent. Total Quality Management. Jakarta : PT. Gramedia Pustaka Utama, 2001.

Griffin, Ricky W. and Ronald J. Ebert. Business, Sixth Edition, International Edition. New Jersey : Prentice Hall International, Inc., 2002.

Griffin,Jill. Customer Loyalty : How to Earn It, How to Keep It. New York : Lexington Books, 1995.

Hausman, Angela. Variations in Relationship Strength and Its Impact on Performance and Satisfaction in Business Relationships, dalam Journal of Business \& Industrial Marketing, Volume 16 No. 7. London : MCB University Press, 2001.

Johnston, Robert. Identifying The Critical Determinants of Service Quality in Retail Banking : Importance and Effect, dalam International Journal of Banking Marketing. London : MCB University Press, 1997.

Kotler, Philip et.al. (Swee Hoon Ang, Siew Meng Leong, Chin Tiong
Tan). Marketing Management An Asian Perspective. Singapore : Prentice Hall, 1996.

Kotler, Philip and Gary Armstrong. Principle of Marketing. Eighth Edition. New Jersey : Prentice Hall, Inc., Englewood Cliff, 1999.

Kotler, Philip. Marketing Management, The Millennium Edition. New Jersey : Prentice Hall International. Inc., 2000.

Kinnear, Thomas C. and Taylor, James R. Marketing Research An Applied Approach. Fifth Edition, New York : McGraw-Hill, Inc., 1996.

Pressey, Andrew D. and Brian P. Mathews. Barriers to Relationship Marketing in Consumer Retailing dalam Journal of Services Marketing. London : MCB University Press, 2001.

Sanders, Donalds H. Statistics A First Course, New York : McGraw-Hill, Inc. 1995 .

Sevilla, Consuelo.G. et.al. An Introduction to Research Methods, Manila : Rex Printing Philippines, 1984.

Siegel, Sidney and N. John Castellan, Jr. NonParametrikc Statistics For the Behavioral Sciences, Second Edition. Singapore : McGraw-Hill Book Company, 1988. 